\title{
Probabilistic assessments of Safety Instrumented Function by considering the justification of cost-benefit using ALARP evaluation method
}

\author{
Amornsak Potiteerabuit, Teerawat Thepmanee \\ Faculty of Engineering \\ King Mongkut's Institute of Technology Ladkrabang \\ Ladkrabang, Bangkok 10520, Thailand \\ amornsak.po@gmail.com; ktteeraw@kmitl.ac.th
}

\begin{abstract}
This paper addresses the conceptual design step that probabilistic calculations are done to show that any given design meets the performance requirements of the Safety Instrumented Function(SIF) by considering the justification of cost-benefit. The average Probability of Failure on Demand $\left(\mathrm{PFD}_{\text {avg }}\right)$ of the one out of one (10o1) sensing device was calculated by simplified Markov model. The effects of the imperfect proof test and proof test interval on the value of $P_{F D}$ avg were then studied. As the test cost occurs during device proof test, high frequently of testing along the device life cycle increases the cost while decreases the $\mathrm{PFD}_{\text {avg }}$ value and risk of the sensing device. In this work, the relationship between the risk reduction achieved and the investment cost was investigated in detail using As Low As Reasonably Practicable (ALARP) method. Based on the ALARP analysis, the optimized interval of proof test was then evaluated.
\end{abstract}

Keywords: SIS, SIF, SIL, PFD, ALARP, Markov model, Proof test

\section{Introduction}

The SIS is a set of instrumentation hardware and software that controls the safety level of the process automation system in order to avoid revolting conditions, such as explosion, fire and leak of hazardous chemicals. Following this look, the desirable safety condition can be managed by implementing SIS to the process system. The IEC standard 61511 (1) defines a Safety Instrumented System (SIS) as an "instrumented system used to implement one or more Safety Instrumented Functions (SIF). A SIS is composed of any combination of sensor, logic solver and final element”. The SIF is intended to bring the process industries to a safe state and designed for protecting the damage to the health of people, property or to the environment.

The level of risk reduction or Safety Integrity Level (SIL) is obtained from the amount of average Probability of Failure on Demand ( $\mathrm{PFD}_{\text {avg }}$ ) of sensing device, logic solve and final element. IEC standard recognizes three modes of safety function operation: (a) Low Demand Mode, (b) High Demand Mode and (c) Continuous Mode (2). The Low Demand Mode is defined as the safety function demand rate is less than or equal to once a year or less than two times of proof test frequency, High Demand Mode is defined as safety function demand rate is greater than once a year or greater than two times of proof test frequency and Continuous Mode is defined as safety function is operating as a continuous control function. This paper focuses on the SIL in Low Demand Mode which is shown in Table 1.

Table 1. Safety Integrity Level (SIL) in Low Demand Mode

\begin{tabular}{|c|c|}
\hline $\begin{array}{c}\text { Safety Integrity Level } \\
\text { (SIL) }\end{array}$ & $\begin{array}{c}\text { Average Probability of Failure on Demand } \\
\left(\mathrm{PFD}_{\text {avg }}\right)\end{array}$ \\
\hline 4 & $\geq 10^{-5}$ to $<10^{-4}$ \\
\hline 3 & $\geq 10^{-4}$ to $<10^{-3}$ \\
\hline 2 & $\geq 10^{-3}$ to $<10^{-2}$ \\
\hline 1 & $\geq 10^{-2}$ to $<10^{-1}$ \\
\hline
\end{tabular}

For decades, many researchers have focused on a variety of SIL assessment and implementation for process safety (3-5) and considered the justification of cost-benefit 
(6). This paper focuses on the proof test of sensing device which affects the $P_{F D}$ avg value by considering the justification of cost-benefit using ALARP evaluation method. The simplified Markov model is taken into account for calculating the $\mathrm{PFD}_{\text {avg. }}$. According to the proof test interval of the sensing device, the test cost will occur. If there are high frequently proof tests along the life cycle of sensing device, the test cost will increase while the risk or $\mathrm{PFD}_{\text {avg }}$ value will decrease respectively. In this case, the As Low As Reasonably Practicable (ALARP) method is taken into account for determining the proper proof test interval.

\section{Markov model and Proof Test method}

The objective of proof test is to reveal the dangerous undetected failures which cannot be detected by online diagnostic test. Once all failures are revealed, the equipment can be repaired and will function as "new" upon restart (3). This proof test is called "Perfect Proof Test". In case of there are remaining dangerous failures which cannot be detected during the proof test, this proof test is called "Imperfect Proof Test". The result from imperfect proof test will impact on the PFD value which will increase every year along the life cycle of device.

The method for determining failure rates is the Failure Modes Effects and Diagnostic Analysis (FMEDA) which is performed by manufacturers. The FMEDA is a systematic technique that is designed to identify problems. It is a "bottom up" method (7) that starts with a detailed list of all components within the system. The result from this analysis will yield the failure rate which is divided in the safe detected failure rate $\left(\lambda^{\mathrm{SD}}\right)$, safe undetected failure rate $\left(\lambda^{\mathrm{SU}}\right)$, dangerous detected failure rate $\left(\lambda^{\mathrm{DD}}\right)$ and dangerous undetected failure rate $\left(\lambda^{\mathrm{DU}}\right)$.

In this paper, the Markov model which is defined as a "memory-less" system where the probability of moving from one state to another is dependent only upon the current state and not past history of getting to the state (7) is taken into account. The failures for calculating the PFD by simplified Markov model are the $\lambda^{\mathrm{DD}}$ and $\lambda^{\mathrm{DU}}$. Other factors for calculating the PFD are Proof Test Coverage (PTC) and Mean Time To Repair (MTTR). The PTC is the ratio of undetected dangerous failures revealed during the proof test to total undetected dangerous failures. The MTTR is the mean time to repair a module or element of the SIS. This mean time (hour) is measured from the time when failure occurs to the time when the repair is completed and device returned to service.
The simplified Markov model shown in Figure 1 consists of three states as following (4).

1) The OK state (state " 0 ", $S_{0}$ ) represents the situation where the SIF is operating correctly with no failures present.

2) The FDD state (state " 1 ", $S_{1}$ ) represents the situation where the SIF failed dangerous detected.

3) The FDU state (state "2", $S_{2}$ ) represents the situation where the SIF failed dangerous undetected.

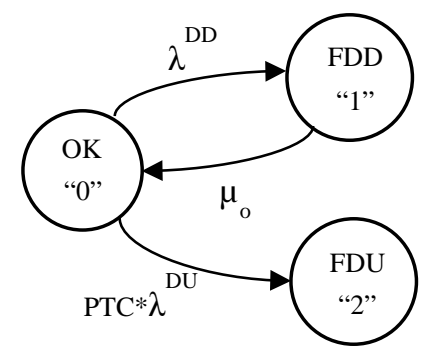

Fig. 1. Simplified Markov model

When the dangerous detected failure occurs, the state " 0 " will move to state " 1 ". If the failure is repaired, the state "1" will move back to state "0" which is represented by Restore rate $\left(\mu_{0}\right)$. Similarly, when the dangerous undetected failure occurs, the state " 0 " will move to state " 2 " and the dangerous undetected failure are only revealed and repaired during proof test.

This paper examines the 1001 sensing device from the manufacturer who performs the FMEDA. $\lambda^{\mathrm{DD}}$ of this device equals $1.898 \mathrm{E}-06$ per hour, $\lambda^{\mathrm{DU}}$ equals $1.730 \mathrm{E}-07$ per hour, MTTR equals 24 hours and suppose that the life cycle $\left(T_{1}\right)$ of device and proof test interval $\left(\mathrm{T}_{\mathrm{i}}\right)$ equals 10 years and every 1 year $(\mathrm{Ti}=1)$ respectively.

The Markov model solution technique which is considered in this paper is numerical solution technique. The probability of being in any state can be obtained by simple matrix (7). To solve for state probabilities, a row

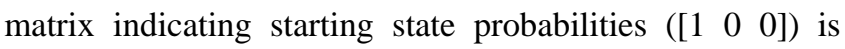
multiplied by the square transition matrix which is shown in Equation (1). Each multiplication represents one discrete time (1 hour) increment. The end of multiplication is at 87600 hours or 10 year which is the device life cycle.
$\mathrm{S}_{0}$ $\mathrm{S}_{1}$ $\mathrm{S}_{2}$
$\left[\begin{array}{lll}1 & 0 & 0\end{array}\right]\left[\begin{array}{ccc}1-\lambda^{D D}-\lambda^{D U} & \lambda^{D D} & P T C * \lambda^{D U} \\ \mu_{0} & 1-\mu_{0} & 0 \\ 0 & 0 & 1\end{array}\right]$ 
From Equation (1), The PFD(t) can be easily calculated by summing $S_{1}$ and $S_{2}$ in each discrete time (each 1 hour) and $\mathrm{PFD}_{\text {avg }}$ can be calculated as follow Equation (2).

$$
P F D_{\text {avg }}=\frac{1}{T_{l}} \int_{0}^{T_{l}} P F D(t) d t
$$

$\mathrm{PFD}_{\text {avg }}$ is average Probability of Failure on Demand

According to this information, Figure 2 shows the $\mathrm{PFD}_{\text {avg }}$ and $\mathrm{PFD}(\mathrm{t})$ of perfect proof test (PTC is $100 \%$ ) but it is quite unrealistic to assume that inspection and testing processes will detect all dangerous undetected failures (7). The suggested proof test from manufacturer will detect 94\% of possible $\lambda^{\mathrm{DU}}$ (PTC is 94\%). According to this imperfect proof test, the $\mathrm{PFD}_{\text {avg }}$ and $\operatorname{PFD}(\mathrm{t})$ are shown in Figure 3.

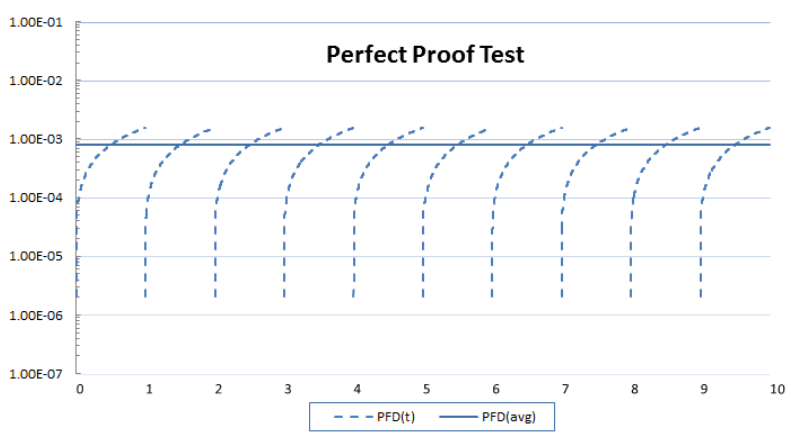

Fig. 2. $\mathrm{PFD}_{\text {avg }}$ and $\mathrm{PFD}(\mathrm{t})$ from the perfect proof test

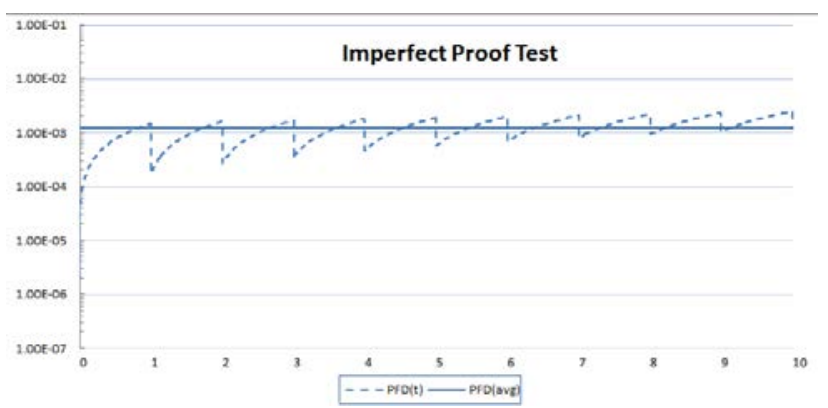

Fig. 3. $P F D_{\text {avg }}$ and $P F D(t)$ from the imperfect proof test

From the Figure 3, It shows that the $\operatorname{PFD}(t)$ is increasing every year along the life cycle of device. The comparison of $\mathrm{PFD}_{\text {avg }}$ between perfect proof test and imperfect proof test in Figure 2 and Figure 3 respectively shows that the $\mathrm{PFD}_{\text {avg }}$ achieving from imperfect proof test is higher than perfect proof test.

\section{ALARP evaluation method}

In fact that the test cost occurs during device proof test, high frequently of testing along the device life cycle increases the cost while decreases the $\mathrm{PFD}_{\text {avg }}$ value or risk of device.

To evaluate the justification of additional test cost and benefit achieving from decreased risk or $\mathrm{PFD}_{\text {avg }}$ whether it is justified or not, the ALARP method which is the demonstrable process whereby "a risk is reduced so low that any further risk reduction would involve time, trouble, difficulty and cost which are grossly disproportionate to the additional risk reduction achieved." (8) is utilized. This method can be used when SIL of SIF is derived from the economic risks only.

The ALARP evaluation is done as follows. See also Figure 4:

1) Design each of the various alternative designs. This paper considers only 1001 sensing device.

2) Establish for each design the required test intervals. The proof test method from manufacturer is considered and the proof test interval is varied from every 1 year, 2 years, 3 years until 10 years along the device life cycle.

3) Do the ALARP evaluation for each improvement step and confirm the selection.

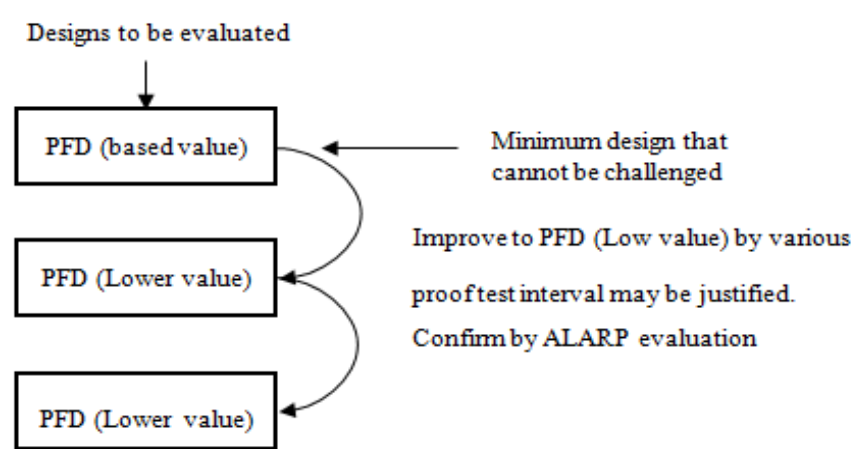

The lowest value of PFD that is still justified reduces the risk to a level that is ALARP.

This is the Proof test interval that is to be selected.

Fig. 4. ALARP evaluation method

To find the ALARP point, the comparison between $\mathrm{PFD}_{\text {avg }}$ and Life Cycle Cost (LCC) of device is considered. The LCC of device is the summation of investment cost of device (including purchase, design and installation) and annual cost (test cost). The annual cost shall be considered in term of present value (PV) at fixed interval by using basic financial which is mentioned by Hary L. Cheddie and 
Paul Grunh (9). The PV can be calculated as follow.

$$
P V=M{\frac{1-[1+R]^{-N}}{R}}^{-N}
$$

Where $\quad \mathrm{M}$ is Annual cost (test cost)

$\mathrm{R}$ is Interest rate (estimated 5\%)

$\mathrm{N}$ is Life cycle of device (10 years)

In this paper, the case study from (6) is taken into account. The information estimates the test cost per event of device equals 150 USD and investment cost of device including purchase, design and installation equals 4,000 USD.

To verify the ALARP point, the Return on Average Capital Employed (ROACE) is utilized to verify whether the benefits are proportionate to additional investment cost or not. The ROACE Equation (4) is expressed as a percentage (\%) and the parameters for calculating the ROACE is shown in Table 2.

$R O A C E=\frac{\text { Benefits }- \text { Depreciation }- \text { Additional } O P E X-N \text { ew risk }}{\text { Additional Investment this alternative }}$

Note: Additional OPEX (Operational Expenditure) is the Test Cost (in case there is different number of device in two designs) and repair cost.

$$
\mathrm{ROACE} \geq \mathrm{ROACE}_{\text {target }}
$$

where ROACE target is the specified minimum ROACE to justify an investment (typically taken from $15 \%$ to $20 \%$ ).

The Equation (4) will be achieved when the number of device in two designs are different. If the two designs are identical where the number of device in this alternative design and lower alternative design are equality, the term “Additional Investment this alternative” is zero. In this case, the ROACE cannot be calculated (8).

This paper considers only one sensing device and the alternative design is different by proof test interval. Only test cost of sensing device is taken into account and the term of "additional OPEX" and "new risk" will be neglected. Therefore, the "Additional Investment this alternative" in Equation (4) will be replaced by "Additional test cost this alternative". The following Equation (6) is considered in this paper.

$$
R O A C E=\frac{\text { Benefits }- \text { Depreciation }}{\text { Additional test cost this alternative }}
$$

\begin{tabular}{|c|c|}
\hline Item & Descriptions \\
\hline $\begin{array}{l}\text { 1. Equivalent } \\
\text { Consequence }\end{array}$ & $\begin{array}{l}\text { For personal safety and environmental consequences, } \\
\text { the equivalent monetary consequences shall be used. } \\
\text { The equivalent money consequences are the logarithmic } \\
\text { average of the value of the lower and upper category } \\
\text { limit of the equivalent 'production loss and equipment } \\
\text { damage category. Logarithmic average is here defined } \\
\text { as: } \quad y=10^{\frac{(\log X 1+\log X 2)}{2}}\end{array}$ \\
\hline $\begin{array}{l}\text { 2.Demand } \\
\text { Interval }\end{array}$ & $\begin{array}{l}\text { is the logarithmic average of the lower and upper limit } \\
\text { of the selected demand rate category. }\end{array}$ \\
\hline 3.Initial Risk & $\begin{array}{l}\text { is the risk without any safety function implemented. It is } \\
\text { calculated as: } \\
\text { Initial Risk }=\frac{\text { Total Equivalent Consequences }}{\text { Demand Interval }}\end{array}$ \\
\hline $\begin{array}{l}\text { 4.Risk } \\
\text { Reduction }\end{array}$ & 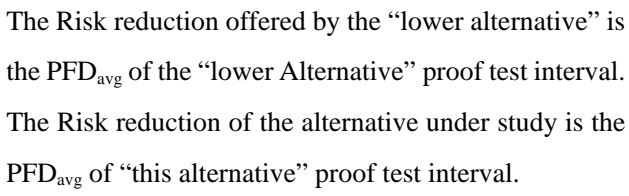 \\
\hline 5.Benefits & $\begin{array}{l}\text { are calculated as: } \\
\text { Benefits } \\
=\left(P F D_{\text {lower alternative }}-P F D_{\text {this alternative }}\right) \times \text { Initial Risk }\end{array}$ \\
\hline $\begin{array}{l}\text { 6.Depreciation } \\
\text { per year }\end{array}$ & $\begin{array}{l}\text { is calculated as: } \\
\text { Depreciation per year } \\
=\frac{\text { Additional investment this alternative }}{\text { Depreciation Period }} \\
\text { In this paper considers as following; } \\
\text { Depreciation per year } \\
=\frac{\text { Additional test cost this alternative }}{\text { Depreciation Period }}\end{array}$ \\
\hline 7.Test Costs & is the test cost per event (USD). \\
\hline 8.Repair Costs & $\begin{array}{l}\text { is the repair cost (USD per hour) (do not consider in this } \\
\text { paper) }\end{array}$ \\
\hline $\begin{array}{l}\text { 9.Additional } \\
\text { test cost }\end{array}$ & $\begin{array}{l}\text { is different test cost between "lower alternative" and } \\
\text { "this alternative" }\end{array}$ \\
\hline $\begin{array}{l}\text { 10.New Risk } \\
\text { (Spurious } \\
\text { Trip Costs) }\end{array}$ & $\begin{array}{l}\text { is the additional cost due to spurious trips by "this } \\
\text { alternative" design (do not consider in this paper). }\end{array}$ \\
\hline
\end{tabular}

Table 2. The Parameters for calculating the ROACE

The case study from (6) which determines SIL of the SIF by using the Risk Graph method is considered. The result from this case study is the demand rate (interval between demands) equals 1 year to 10 years, the economic 
consequence equals 1 million USD which is in category $\mathrm{L}_{3}$, there is slight effect of environmental consequence which is in category $E_{1}$ and there is no personal injury or health effect which is in category $\mathrm{C}_{0}$. From Table 2, the total equivalent consequence which is summation of economic, personal health and environmental consequence equals 319706.27, the demand rate equals 3.16. From both parameters, the initial risk can be calculated. Therefore, the initial risk equals 101100.

\section{Experimental Result}

To determine the ALARP point, the $\mathrm{PFD}_{\text {avg }}$ and Life Cycle Cost (LCC) of each proof test interval shall be calculated then the comparison between these parameters is plotted into the graph and the ALARP point will be verified by ROACE whether the benefits are proportionate to additional test cost or not. The ALARP point can be determined by the following step.

\section{1 $\quad$ PFD $_{\text {avg }}$ and Life Cycle Cost (LCC) calculation}

The PFD value can be calculated by Equation $(1,2)$. The LCC can be calculated by investment cost and test cost Equation (3). The results of these calculations are shown in Table 3 and the Figure 5 is the comparison graph between PFD $_{\text {avg }}$ and LCC of each proof test interval.

Table 3. PFD ${ }_{\text {avg }}$ and Life Cycle Cost (LCC)

\begin{tabular}{|c|c|c|}
\hline $\begin{array}{c}\text { Proof test interval } \\
(\mathrm{Ti})\end{array}$ & PFD $_{\text {avg }}$ & Life Cycle Cost (USD) \\
\hline $\mathrm{Ti}=1$ & $1.21 \mathrm{E}-03$ & 15,583 \\
\hline $\mathrm{Ti}=2$ & $1.83 \mathrm{E}-03$ & 9,791 \\
\hline $\mathrm{Ti}=3$ & $2.36 \mathrm{E}-03$ & 7,861 \\
\hline $\mathrm{Ti}=4$ & $2.88 \mathrm{E}-03$ & 6,896 \\
\hline $\mathrm{Ti}=5$ & $3.81 \mathrm{E}-03$ & 6,317 \\
\hline $\mathrm{Ti}=6$ & $3.94 \mathrm{E}-03$ & 5,930 \\
\hline $\mathrm{Ti}=7$ & $4.34 \mathrm{E}-03$ & 5,655 \\
\hline $\mathrm{Ti}=8$ & $5.01 \mathrm{E}-03$ & 5,448 \\
\hline $\mathrm{Ti}=9$ & $5.95 \mathrm{E}-03$ & 5,287 \\
\hline $\mathrm{Ti}=10$ & $7.13 \mathrm{E}-03$ & 5,158 \\
\hline
\end{tabular}

The Figure 5 shows that the high frequency of proof test along the device life cycle increases LCC while decreases the risk or $\mathrm{PFD}_{\text {avg. }}$. The intersection between $\mathrm{Ti}=3$ and $\mathrm{Ti}=4$ is the ALARP point.

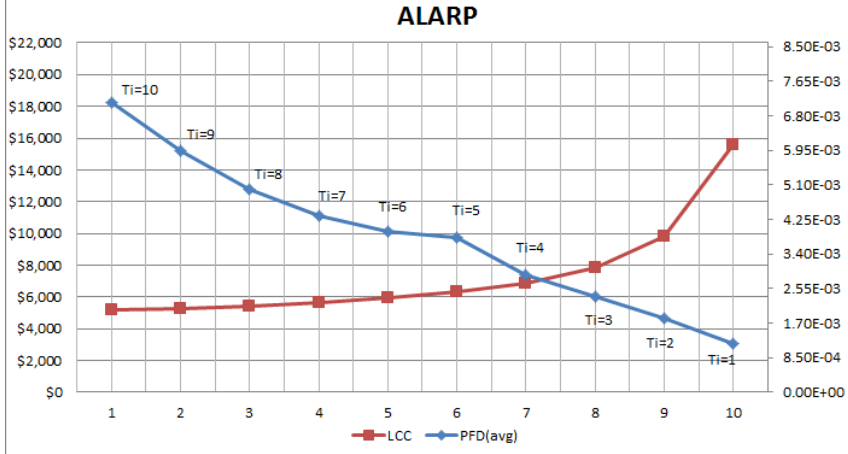

Fig. 5. Comparison Graph between PFD $_{\text {avg }}$ and LCC

The risk reduction from $\mathrm{Ti}=10$ to $\mathrm{Ti}=4$ is proportionate to the investment cost but risk reduction from $\mathrm{Ti}=3$ to $\mathrm{Ti}=1$ is not proportionate to investment cost because risk reduction which is minor comparing with high LCC. Therefore, the selected proof test interval which is justified is $T i=4$.

\subsection{ROACE calculation for verifying ALARP}

To verify whether the selected proof test interval $(\mathrm{Ti}=4)$ can reduce the risk or $\mathrm{PFD}_{\text {avg }}$ to the ALARP point, ROACE method is utilized.

Table 4. PFD $_{\text {avg, }}$, Proof test frequency and Test cost

\begin{tabular}{|c|c|c|}
\hline $\begin{array}{c}\text { Proof test interval } \\
(\mathrm{Ti})\end{array}$ & $\begin{array}{c}\text { Proof test frequency per life } \\
\text { cycle of device (Time) }\end{array}$ & $\begin{array}{c}\text { Test cost } \\
\text { (USD) }\end{array}$ \\
\hline $\mathrm{Ti}=1$ & 10.0 & 1,500 \\
\hline $\mathrm{Ti}=2$ & 5.0 & 750 \\
\hline $\mathrm{Ti}=3$ & 3.3 & 500 \\
\hline $\mathrm{Ti}=4$ & 2.5 & 375 \\
\hline $\mathrm{Ti}=5$ & 2.0 & 300 \\
\hline $\mathrm{Ti}=6$ & 1.7 & 250 \\
\hline $\mathrm{Ti}=7$ & 1.4 & 214 \\
\hline $\mathrm{Ti}=8$ & 1.3 & 188 \\
\hline $\mathrm{Ti}=9$ & 1.1 & 167 \\
\hline $\mathrm{Ti}=10$ & 1.0 & 150 \\
\hline
\end{tabular}

The Table 4 shows proof test interval, proof test frequency along the device life cycle and test cost. The ROACE calculation in Table 2 is done as follows.

1) Equivalent Consequence and Demand interval are calculated from the information from (6)

2) Calculate the Initial Risk from item 3

3) Calculate the Benefits from the item 5

4) Calculate the additional test cost from item 9 and Table 4 
5) Calculate the Depreciation from the item 6

The comparison of respective proof test interval and ROACE value calculated from these steps are shown in Table 5.

Table 5. Comparison of proof test interval and ROACE

\begin{tabular}{|c|c|c|c|c|}
\hline $\begin{array}{c}\text { Comparison of } \\
\text { respective proof } \\
\text { test interval }\end{array}$ & Benefits & $\begin{array}{c}\text { Additional } \\
\text { test cost } \\
\text { (USD) }\end{array}$ & Depreciation & $\begin{array}{c}\text { ROACE } \\
(\%)\end{array}$ \\
\hline $\mathrm{Ti}=1$ and $\mathrm{Ti}=2$ & 63.15 & 750.00 & 75.00 & $-1.58 \%$ \\
\hline $\mathrm{Ti}=2$ and $\mathrm{Ti}=3$ & 53.15 & 250.00 & 25.00 & $11.26 \%$ \\
\hline $\mathrm{Ti}=3$ and $\mathrm{Ti}=4$ & 53.18 & 125.00 & 12.50 & $32.54 \%$ \\
\hline $\mathrm{Ti}=4$ and $\mathrm{Ti}=5$ & 93.86 & 75.00 & 7.50 & $115.15 \%$ \\
\hline $\mathrm{Ti}=5$ and $\mathrm{Ti}=6$ & 13.16 & 50.00 & 5.00 & $16.31 \%$ \\
\hline $\mathrm{Ti}=6$ and $\mathrm{Ti}=7$ & 40.30 & 35.71 & 3.57 & $102.85 \%$ \\
\hline $\mathrm{Ti}=7$ and $\mathrm{Ti}=8$ & 67.61 & 26.79 & 2.68 & $242.42 \%$ \\
\hline $\mathrm{Ti}=8$ and $\mathrm{Ti}=9$ & 95.09 & 20.83 & 2.08 & $446.44 \%$ \\
\hline $\mathrm{Ti}=9$ and $\mathrm{Ti}=10$ & 119.68 & 16.67 & 1.67 & $708.08 \%$ \\
\hline
\end{tabular}

According to Equation (5), the selected proof test interval will be justified when ROACE $\geq$ ROACE target where minimum ROACE target is 15\%. Therefore, the selected proof test interval which is justified is $\mathrm{Ti}=4$ (proof test 2.5 times per device life cycle).

\section{Conclusion}

This paper focuses only on 1001 sensing device. The $\mathrm{PFD}_{\mathrm{avg}}$ of sensing device is calculated by simplified Markov model. The different proof test interval is taken into account in this study and this factor significantly impacts on the risk or $\mathrm{PFD}_{\mathrm{avg}}$ value. The risk or $\mathrm{PFD}_{\mathrm{avg}}$ can be reduced by increasing proof test interval. In this case, the test cost occurs when proof test of device is performed.

To demonstrate that the increased test cost is proportionate to risk reduction or decreased $\mathrm{PFD}_{\mathrm{avg}}$, the ALARP method is a tool for determining that the selected proof test is justified and this method can only be used when SIL of SIF is derived from the economic risks.

The optimized proof test interval of sensing device in this paper is $\mathrm{Ti}=4$ which is done by proof testing 2.5 times per device life cycle and the $\mathrm{PFD}_{\mathrm{avg}}$ of this proof test interval is $2.88 \mathrm{E}-03$.

Finally, the $\mathrm{PFD}_{\text {avg }}$, ALARP calculation method and proof test interval selection in this paper can also be used for final element which is the one of three parts in Safety Instrumented System (SIS).

\section{References}

(1) IEC-61511 : "Functional safety - Safety instrumented systems for the process industry sector”, Inter-national Electrotechnical Commission, 2003

(2) IEC-61508 : "Functional safety of electrical / electronic / programmable electronic safety-related systems”, International Electrotechnical Commission, 2000

(3) Walid MECHRI, Christophe SIMON, Frdrique BICKING and Kamel BEN OTHMAN : "Probability of Failure on Demand of safety systems by Multiphase Markov Chains”, Control and Fault-Tolerant Systems (SysTol), pp. 98-103, 2013

(4) Bukowski J.V and Iwan van Beurden : "Impact of Proof Test Effectiveness on Safety Instrumented System Performance”, Reliability and Maintainability Symposium, pp. 157-163, 2009

(5) Teerawat Thepmanee and Pornpatchara Khamkoon "SIL Assessment and implementation case study: A safety instrumented function for overpressure protection in a two - phase gas - liquid separator", ICIC Express Letters Part B: Applications Volume 5, Number 1, February 2014, pp. 45 - 50.

(6) Pornpatchara Khamkoon : "SIL Assessment and Design of Safety Instrumented Function by considering the justification of cost-benefit using ALARP evaluation method”, KMITL-2014-EN-M-257-26

(7) William M. Goble and Harry L. Cheddie : "Safety Instrumented Systems Verification: Practical Probabilistic Calculations”, ISA, 2005

(8) Shell GSI : "Classification and Implementation of Instrumented Protective Functions”, DEP 32.80.10.10 - Gen (Shell Standard), 2010

(9) Harry L. Cheddie and Paul Gruhn : "Safety Instrumented System: Design, Analysis, and Justification”, $2^{\text {nd }}$ Edition ,ISA, 2002 